\title{
Occurrence of Cicadulina bipunctata (Hemiptera: Cicadellidae) in southwestern Shikoku, Japan and comparisons of gall-inducing ability between Kyushu and Shikoku populations
}

\author{
Shun Kumashiro $\cdot$ Keiichiro Matsukura • \\ Ryo Ogawa · Masaya Matsumura · Makoto Tokuda
}

Received: 2 July 2013/Accepted: 19 February 2014/Published online: 8 March 2014

(c) The Author(s) 2014. This article is published with open access at Springerlink.com

\begin{abstract}
The maize orange leafhopper Cicadulina bipunctata (Melichar) is an insect pest of cereal crops in tropical and subtropical regions of the Old World. This leafhopper induces gall symptoms characterized by stunted growth and swollen leaf veins on various Poaceae. Damage by $C$. bipunctata has been reported from Australia, the Philippines, China, Taiwan, and Japan. In Japan, C. bipunctata occurs in the central and southern parts of Kyushu. Because the leafhopper is a potential pest of various cereal crops, we conducted field surveys in Shikoku and the southern part of the Kii Peninsula (a part of Honshu), where the climate seems to be suitable for the establishment of $C$. bipunctata. As a result, we found $C$. bipunctata at some localities in Ehime and Kochi Prefectures. This is the first record of this leafhopper from Shikoku. Our laboratory experiment revealed that a Kochi population of $C$.
\end{abstract}

Electronic supplementary material The online version of this article (doi:10.1007/s13355-014-0253-3) contains supplementary material, which is available to authorized users.

S. Kumashiro $(\bowtie)$

The United Graduate School of Agricultural Sciences,

Kagoshima University, Korimoto, Kagoshima 890-0065, Japan

e-mail: riesz_eilis3@yahoo.co.jp

K. Matsukura · M. Matsumura

Agro-Environment Research Division, NARO Kyushu Okinawa Agricultural Research Center, Koshi, Kumamoto 861-1192, Japan

\section{R. Ogawa}

Entomological Laboratory, Faculty of Agriculture Ehime University, Tarumi, Matsuyama, Ehime 790-8566, Japan

\section{Tokuda}

Laboratory of Systems Ecology, Faculty of Agriculture, Saga

University, Honjo, Saga 840-8502, Japan bipunctata had a gall inducing ability similar to the Kumamoto population. More attention should be paid to assessing the risk of further expansion of $C$. bipunctata populations in Shikoku.

Keywords Distribution - Maize orange leafhopper . Maize wallaby ear symptom · Poaceae

\section{Introduction}

Maize orange leafhopper, Cicadulina bipunctata (Melichar), is distributed in tropical and subtropical regions of the Old World (Webb 1987; Matsukura et al. 2009a). In Japan, this species is known to occur in the Bonin Islands (Matsumura 1914), the Ryukyu Islands (Hayashi 2002), and Kyushu (Matsumura et al. 2006; Matsukura et al. 2009a; Kumashiro et al. 2012). The leafhopper feeds on various Poaceae including important crops, such as maize, rice and wheat (Maramorosch et al. 1961; Catindig et al. 1996; Kumashiro et al. 2011). Cicadulina bipunctata is a serious pest of maize because feeding by the leafhopper induces gall symptoms characterized by stunted growth and swollen leaf veins, which is referred to as the maize wallaby ear symptom (Grylls 1975; Ohata 1993). The symptoms have been reported from Australia (Grylls 1975), the Philippines (Agati and Calica 1949; Maramorosch et al. 1961), China ( $\mathrm{Li}$ and Liu 2004; Li et al. 2004), Taiwan (Chen 1991), and Japan (Ohata 1993; Matsumura et al. 2005, 2006).

Although previous studies attributed the symptoms to a leafhopper-transmitted virus (Agati and Calica 1949; Maramorosch et al. 1961; Grylls 1975; Reddy et al. 1976; Boccardo et al. 1980), recent studies have recognized that some chemicals injected by $C$. bipunctata during feeding 
are responsible for gall induction (Ofori and Francki 1983; Ohata 1993; Kawano 1994; Matsukura et al. 2012a). Galls are induced only on leaves which are newly expanding during leafhopper feeding, but not on leaves already developed or those which expand after the removal of leafhoppers (Ofori and Francki 1983; Ohata 1993; Matsukura et al. 2009b). The degree of gall induction depends on the density and duration of feeding by $C$. bipunctata (Matsukura et al. 2009a; Matsukura and Matsumura 2010; Tokuda et al. 2013).

In Japan, the gall symptom was first reported in Kumamoto and Okinawa Prefectures in the late 1980s (Ohata 1993; Kawano 1994). Heavy damage occurred on the second planting of forage maize, especially in Kumamoto Prefecture (Ohata 1993). According to Matsumura et al. (2005), the total area of forage maize fields damaged by $C$. bipunctata has expanded gradually since 2001 in Kumamoto Prefecture, and outbreaks of the leafhopper were reported in 2004. Thereafter, a resistant maize variety was developed to reduce the damage caused by $C$. $b i$ punctata (Tokuda and Matsumura 2005).

Because $C$. bipunctata has a certain degree of tolerance to high temperatures, such as 31 and $34^{\circ} \mathrm{C}$ (Tokuda and Matsumura 2005), the expansion of distribution range following global warming is of concern for this species (Matsumura et al. 2005; Matsukura et al. 2009a, 2012b). Cicadulina bipunctata occurs in the southern parts and middle-western parts of Kyushu (Webb 1987; Matsukura et al. 2009a), and our most recent study revealed that the leafhopper is also distributed in the middle-eastern parts, but not in the northern parts, of Kyushu (Kumashiro et al. 2012). Until now, C. bipunctata had not been reported from Shikoku or the Kii Peninsula, Honshu, even though the annual mean temperatures of these areas are rather higher than in the middle parts of Kyushu (Japan Meteorological
Agency 2011). This implies that the climate in these areas would permit the survival of $C$. bipunctata.

To assess the potential risk of agricultural damage by $C$. bipunctata, information about the detailed distribution of C. bipunctata and its gall-inducing ability in local populations will be very important. In this study, we surveyed the distribution of $C$. bipunctata in the southwestern and eastern parts of Shikoku and the southwestern part of the Kii Peninsula, and we compared the gall inducing ability of C. bipunctata between Kyushu and Shikoku populations.

\section{Materials and methods}

Field survey

Field investigations were conducted in 17 localities in Ehime Prefecture and in 16 localities in Kochi Prefecture, southwestern Shikoku, Japan in November 2011. Additional investigations were performed in 8 localities in Kagawa Prefecture, 11 localities in Tokushima Prefecture, eastern Shikoku and 18 localities in Wakayama Prefecture, southwestern Kii Peninsula in October 2012 (Table 1 and Supplementary Table 1). In each locality, the grasslands where host grassy weeds of $C$. bipunctata such as Eleusine indica (L.), Digitaria ciliaris (Retz.), and Setaria viridis (L.) grew were selected for the census sites and 30 or 25 sweeps using a sweeping net with a diameter of $42 \mathrm{~cm}$ were performed at each census site. The census sites were separated from each other by at least $2 \mathrm{~km}$. Collected leafhoppers were kept in glass tubes filled with $99.5 \%$ ethanol, but approximately 40 adults collected from a census site in Kochi (Ohtsu, see Fig. 1; Table 1) were transferred alive to Kyushu Okinawa Agricultural Research Center in Kumamoto and reared on rice seedlings at $25{ }^{\circ} \mathrm{C}$
Table 1 Collection sites and numbers of $C$. bipunctata captured in Ehime Prefecture

Sites where $C$. bipunctata was not found are shown in Supplementary Table 1

\begin{tabular}{lllrrrr}
\hline No. & Census site & $\begin{array}{l}\text { Longitude } \\
(\mathrm{N})\end{array}$ & Latitude (E) & Male & Female & Total \\
\hline 1 & Shimodomari, Mikame Town, Seiyo City, & $33^{\circ} 20^{\prime} 05.7$ & $132^{\circ} 22^{\prime} 41.2$ & 19 & 7 & 26 \\
& $\quad$ Ehime & & & & & \\
2 & Karihama, Akehama Town, Seiyo City, Ehime & $33^{\circ} 18^{\prime} 36.9$ & $132^{\circ} 26^{\prime} 46.9$ & 0 & 2 & 2 \\
3 & Sunokawa, Ainan Town, Ehime & $33^{\circ} 01^{\prime} 48.0$ & $132^{\circ} 28^{\prime} 56.1$ & 1 & 2 & 3 \\
4 & Ohtsu, Tosashimizu City, Kochi & $32^{\circ} 45^{\prime} 03.9$ & $132^{\circ} 47^{\prime} 01.0$ & 31 & 32 & 63 \\
5 & Tsumajiro, Tosashimizu City, Kochi & $32^{\circ} 47^{\prime} 16.1$ & $132^{\circ} 52^{\prime} 13.5$ & 1 & 0 & 1 \\
6 & Nakanohama, Tosashimizu City, Kochi & $32^{\circ} 46^{\prime} 22.9$ & $132^{\circ} 57^{\prime} 52.4$ & 1 & 3 & 4 \\
7 & Ashizurimisaki, Tosashimizu City, Kochi & $32^{\circ} 43^{\prime} 17.4$ & $133^{\circ} 00^{\prime} 39.9$ & 1 & 2 & 3 \\
8 & Kubotsu, Tosashimizu City, Kochi & $32^{\circ} 46^{\prime} 57.2$ & $132^{\circ} 59^{\prime} 36.6$ & 3 & 7 & 10 \\
9 & Ukibuchi, Kuroshio Town, Kochi & $32^{\circ} 59^{\prime} 33.4$ & $133^{\circ} 00^{\prime} 25.6$ & 1 & 0 & 1 \\
10 & Shirahama, Kuroshio Town, Kochi & $33^{\circ} 02^{\prime} 26.3$ & $133^{\circ} 05^{\prime} 48.2$ & 18 & 24 & 42 \\
11 & Okitsu, Shimanto Town, Kochi & $33^{\circ} 09^{\prime} 45.9$ & $133^{\circ} 12^{\prime} 24.3$ & 60 & 74 & 134 \\
\hline
\end{tabular}


Fig. 1 Census sites for $C$. bipunctata in Shikoku and the Kii Peninsula. Sites where $C$. bipunctata was found are marked by solid circles with site numbers shown in Table 1 and those where it was not found are shown with open circles or squares

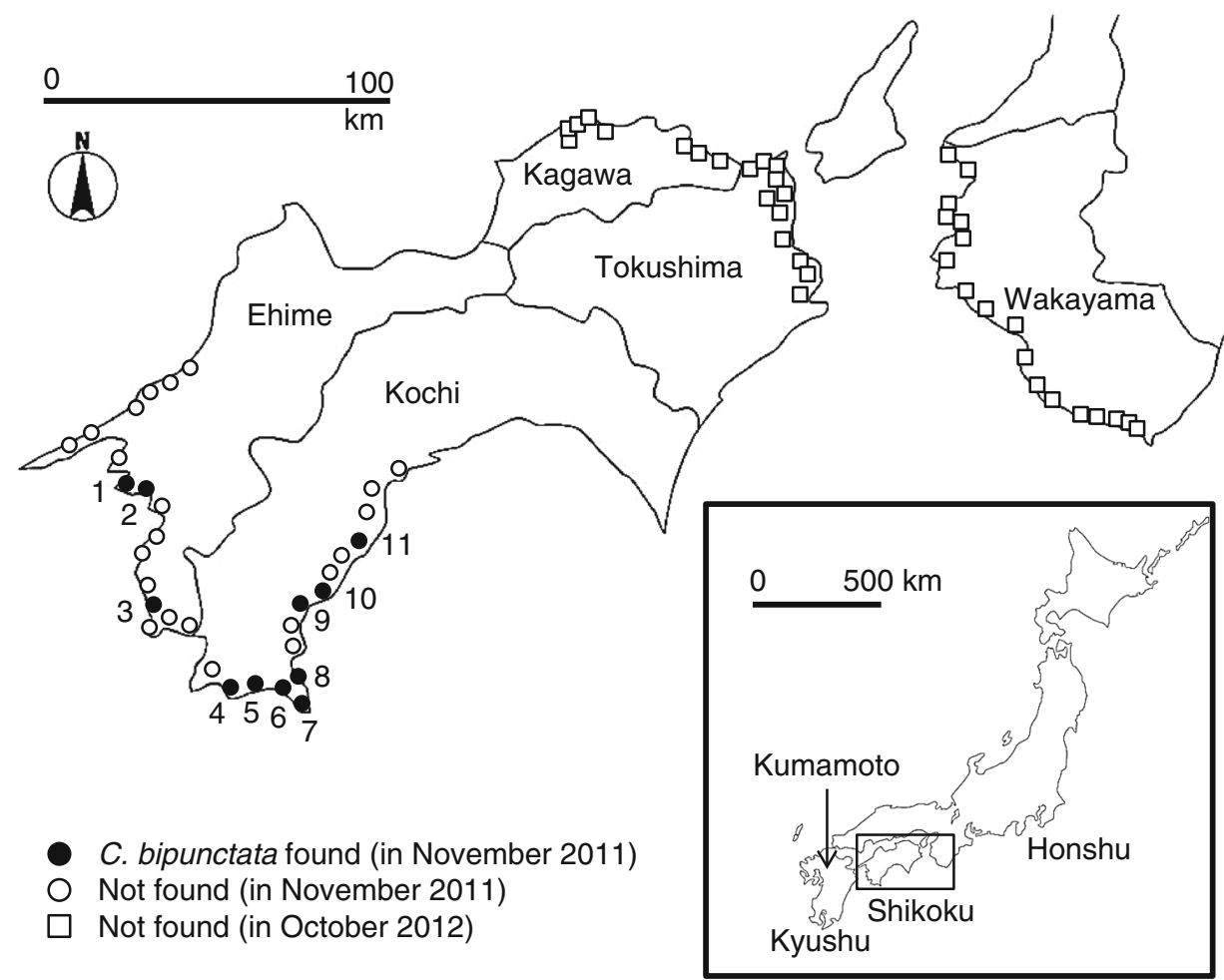

under a 16L: 8D photoperiod, as in Matsumura and Tokuda (2004).

\section{Gall-inducing ability}

In order to compare the gall-inducing ability of $C$. bipunctata between Kyushu and Shikoku populations, the following two stock cultures, Kumamoto and Kochi populations, of C. bipunctata were used in this study. The Kumamoto population was established from approximately 70 adults collected from Shisui, Kumamoto, Kyushu in December 2012 and the Kochi Population was established from ca. 40 adults collected from Ohtsu, Kochi, Shikoku in November 2011 (Fig. 1; Table 1; No. 4). Both populations were reared on rice seedlings (a japonica type rice variety Reiho) following the method described in Matsumura and Tokuda (2004). Two maize varieties, 3470 and 30D44 were used as plant hosts. The former is susceptible to feeding by $C$. bipunctata (Matsukura and Matsumura 2010). Though the latter is known as a resistant variety, it suffers severe symptoms when it is infested by $C$. bipunctata at younger stages (1-5 weeks after sowing) (Matsukura and Matsumura 2010).

Both of the maize varieties were individually sown in plastic cups $(220 \mathrm{ml})$ with soil, and kept in a phytotron at $25{ }^{\circ} \mathrm{C}$ under a 16L: 8D photoperiod. Seven days after sowing, when seedlings reached the second (var. 3470) or third leaf stage (var. 30D44), zero (=control) or five adult males (less than 7 days after emergence) of either Kumamoto or Kochi populations were released on each seedling.
Prior to the release of males, all plants were covered individually with an acrylic cylinder $(4.5 \mathrm{~cm}$ diameter and $24.5 \mathrm{~cm}$ high) with nylon cloth on the top for ventilation. Seven days after the release, all males were removed from the plants and the number of surviving individuals was counted.

As mentioned earlier, galls of $C$. bipunctata are induced on leaves newly expanding during leafhopper feeding. Thus, the length of the third (var. 3470) or fourth (var. 30D44) leaf was measured from the base of plant to the tip of plant (an equivalent measurement to leaf length often used in monocotyledons) 7 days after the removal of males, when seedlings of both varieties reached the fourth and early fifth leaf stages, respectively. Then the symptom scores (Matsumura and Tokuda 2004) of these leaves were evaluated as described below. The gall symptoms were classified into the following three categories according to its severity: (0) no visible symptoms; (1) leaf veins partially rising; and (2) leaf veins heavily swollen (Matsumura and Tokuda 2004). Ten replications were conducted.

Statistical analysis

The number of surviving $C$. bipunctata males was analyzed by analysis of variance (two-way ANOVA) followed by the Tukey HSD test. To compare the effect of feeding by $C$. bipunctata on the degree of stunted growth, the leaf length was analyzed by planned comparisons (Sokal \& Rohlf 1995) between control and treatments (Kumamoto and 
Kochi populations of $C$. bipunctata) for each maize variety, followed by the comparison between the two populations. The differences in the mean symptom scores between the leafhopper populations were assessed by Wilcoxon ranksum test for each maize variety. All analyses except the planned comparisons were performed with $\mathrm{R}$ software, version 2. 12. 2 (R Development Core Team 2011).

\section{Results}

Distribution of C. bipunctata in Shikoku and the Kii

Peninsula

Cicadulina bipunctata was collected from three out of 17 sites $(17.6 \%)$ in Ehime and eight out of 16 sites $(50.0 \%)$ in Kochi Prefecture (Fig. 1; Table 1). More than 40 individuals of $C$. bipunctata were collected from each of three census sites in Kochi Prefecture (Fig. 1; Table 1; Nos. 4, 10, and 11), but less than 30 individuals from each of the other sites. Cicadulina bipunctata was found at all census sites on Cape Ashizuri in Kochi (Fig. 1; Table 1; Nos. 6, 7, and 8). In contrast, the leafhopper was not collected from northern census sites of Ehime Prefecture (Fig. 1). In addition, no $C$. bipunctata was collected from all 19 sites in eastern Shikoku or 18 sites in the southwestern Kii Peninsula (Fig. 1 and Supplementary Table 1).

\section{Gall-inducing ability}

Both maize varieties and leafhopper populations did not affect the number of surviving $C$. bipunctata (two-way ANOVA, variety $F_{1,36}=0.69, \quad p=0.40 ;$ population

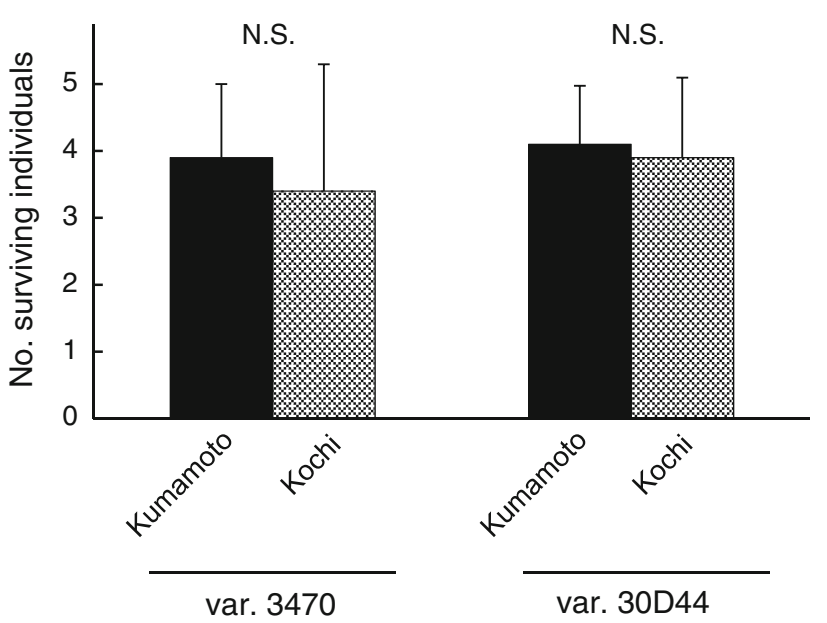

Fig. 2 The number of surviving $C$. bipunctata of Kumamoto and Kochi populations 7 days after the release onto susceptible (3470) and resistant (30D44) maize varieties. Vertical bars show the standard deviation
$F_{1,36}=0.69, p=0.40 ;$ variety $\times$ population $F_{1,36}=0.12$, $p=0.72$; Fig. 2).

Both the Kumamoto and Kochi populations induced gall symptoms on susceptible and resistant maize varieties. On the susceptible variety 3470 , the length of the third leaf infested by $C$. bipunctata was significantly shorter than that of the control $\left(F_{1,27}=13.67, p<0.005\right.$; Fig. 3$)$, but the severity of stunting was not significantly different between the two populations $\left(F_{1,27}=3.04, p>0.05\right.$; Fig. 3$)$. On the resistant variety 30D44, leaves infested by $C$. bipunctata were significantly shorter than the control

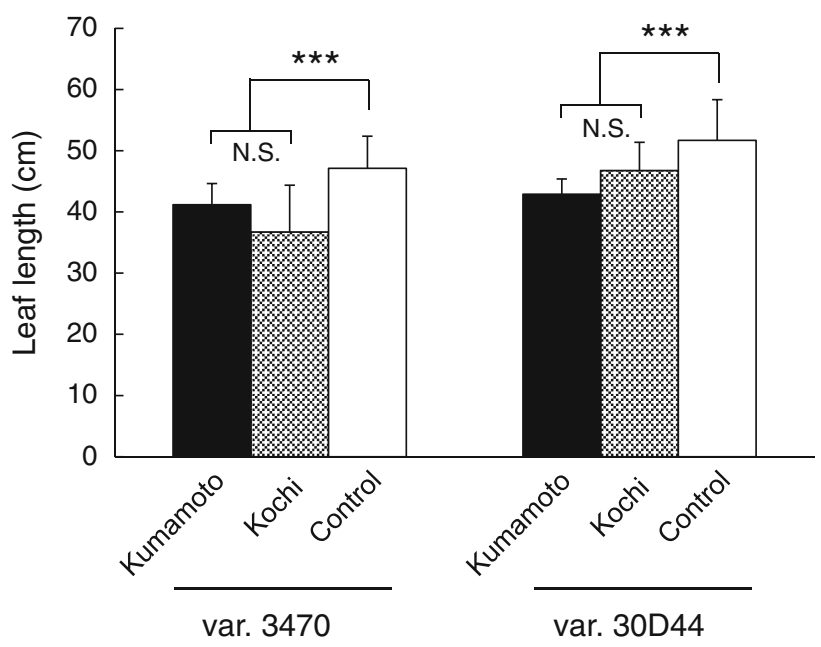

Fig. 3 Effect of feeding by Kumamoto and Kochi population on growth stunting of susceptible (3470) and resistant (30D44) maize varieties. Vertical bars show the standard deviation. Asterisks indicate significant differences (planned comparisons, $* p<0.05$, $* * p<0.01$, $* * * p<0.005)$

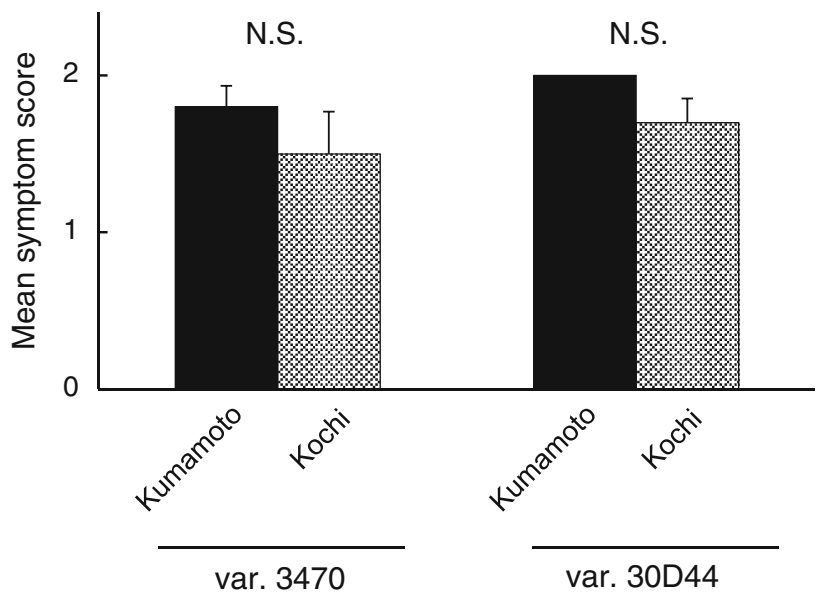

Fig. 4 Effect of feeding by the Kumamoto and Kochi populations of C. bipunctata on the leaf vein swelling of susceptible (3470) and resistant (30D44) maize varieties. The degree of leaf vein swelling was assessed by the symptom score ( 0 no visible symptoms, 1 leaf veins partially swelling, 2 leaf veins heavily swelling). Vertical bars show the standard errors 
$\left(F_{1,27}=13.11, p<0.005\right.$; Fig. 3$)$. The leaf length was not significantly different between the Kumamoto and Kochi populations $\left(F_{1,27}=3.11, p>0.05\right.$; Fig. 3$)$.

As shown in high symptom scores (Fig. 4), maize leaf veins were heavily swollen by infestation in both varieties. The degree of leaf vein swelling was not significantly different between Kumamoto and Kochi populations on both $3470(N=10$, Wilcoxon rank-sum test, $W=43$, $p=0.51)$ and 30D44 $(N=10$, Wilcoxon rank-sum test, $W=35, p=0.076$ ) (Fig. 4). No leaf vein swellings were induced on control plants (Data not shown).

\section{Discussion}

Our field survey revealed that $C$. bipunctata occurs in Ehime and Kochi Prefectures. This is the first collection record of this species from Shikoku. In this study, C. $b i$ punctata was found only in southwestern Shikoku, the area closest to central Kyushu (Fig. 1). On the other hand, the leafhopper was not collected from eastern Shikoku or the southwestern Kii Peninsula, far from Kyushu (Fig. 1). These results suggest that the $C$. bipunctata found in southwestern Shikoku are possibly due not to humanmediated long-distance dispersal but to natural short-distance dispersal such as wind-mediated and flight dispersal. Indeed, some species of the genus Cicadulina other than $C$. bipunctata are known to have the ability to fly continuously over several hours (Rose 1972).

Other invasive pest species such as Liriomyza trifolii (Burgess) (Saito 1992; Ozawa 2002) and Aleurocanthus camelliae Kanmiya \& Kasai (Kasai et al. 2010) have dispersed throughout Japan within 10 years. This rapid dispersal is attributed to the human transportation of infested host plants (Saito 1992; Kasai et al. 2010). In contrast, the maize plants inhabited by $C$. bipunctata are seldom transported alive by people. Thus, C. bipunctata would not disperse as rapidly as the above mentioned species. Indeed, the distribution of $C$. bipunctata has been restricted to small areas even a hundred years after they were first detected in central Kyushu (Matsumura 1914; Matsukura et al. 2009a). More extensive investigation, however, will be required to determine the distribution range of $C$. bipunctata.

The warm climate in Shikoku and the Kii Peninsular (similar to that in central Kyushu) would allow the colonization and reproduction of $C$. bipunctata in these areas once it invades or is introduced there. In particular, the eastern part of Shikoku is at risk of $C$. bipunctata invasion from neighboring source habitats. Further expansion of $C$. bipunctata towards the northern and eastern part of Japan, therefore, should be monitored carefully.
As mentioned earlier, $C$. bipunctata is recognized as a serious pest of the second planting of forage maize in central Kyushu, Japan (Ohata 1993; Matsumura et al. 2006). Although damage caused by $C$. bipunctata on cereal crops has not yet been reported in Shikoku, the present results clearly indicate that $C$. bipunctata has a potential to become a serious pest of poaceous crops in Shikoku as well as in Kyushu. In addition, the present results suggest that the Kochi population is similar to the Kumamoto population in the ability to induce growth stunting and leaf vein swellings on susceptible and resistant varieties (Figs. 3, 4). We will need to pay further attention to the possible distribution, expansion, and growth of $C$. bipunctata populations in Japan.

Acknowledgments We thank Dr. K. M. Harris for reviewing an early draft and Ms. K. Abe and Ms. R. Yamada for rearing the insects for experiments. This study was supported in part by Grants-in-Aid for JSPS fellows (24. 2812) to SK, Scientific Research on Innovative Areas (21200066) from MEXT, Japan to MT, and Development of mitigation and adaptation techniques to global warming in the sectors of agriculture, forestry, and fisheries (44130) from the Ministry of Agriculture, Forestry, and Fisheries of Japan to KM.

Open Access This article is distributed under the terms of the Creative Commons Attribution License which permits any use, distribution, and reproduction in any medium, provided the original author(s) and the source are credited.

\section{References}

Agati JA, Calica C (1949) The leaf-gall disease of rice and corn in the Philippines. Philipp J Agric 14:31-40

Boccardo G, Hatta T, Francki RIB, Grivell CJ (1980) Purification and some properties of reovirus-like particles from leafhoppers and their possible involvement in wallaby ear disease of maize. Virology 100:300-313

Catindig JLA, Barrion AT, Litsinger JA (1996) Plant host range and life history of the orange leafhopper Cicadulina bipunctata (Melichar) (Hemiptera: Cicadellidae). Philipp Entomol 10:163-174

Chen CC (1991) The plant diseases transmitted by the leafhoppers and planthoppers in Taiwan. Chin J Entomol 7:139-156 (in Chinese)

Grylls NE (1975) Leafhopper transmission of a virus causing maize wallaby ear disease. Ann Appl Biol 79:283-296

Hayashi M (2002) Homoptera. In: Azuma S (ed) Check list of the insect of the Ryukyu Islands, Flora and Fauna in Okinawa No. 1, 2nd edn. Biological Society of Okinawa, Okinawa, pp 97-112 (in Japanese)

Japan Meteorological Agency (2011) http://www.jma.go.jp/

Kasai A, Yamashita K, Yoshiyasu Y (2010) Tea-infesting population of the citrus spiny whitefly, Aleurocanthus spiniferus (Homoptera: Aleyrodidae), does not accept citrus leaves. Jpn J Appl Entomol Zool 54:140-143 (in Japanese with English summary)

Kawano S (1994) Occurrence of maize [Zea mays] disorder induced by the feeding of the leafhopper, Cicadulina bipunctella (Matsumura) (Hemiptera: Cicadellidae) in Okinawa, Japan. Bull Okinawa Agric Exp Stn 15:51-57 (in Japanese with English summary) 
Kumashiro S, Matsukura K, Kawaura K, Matsumura M, Ogihara Y, Tokuda M (2011) Effect of barley chromosome addition on the susceptibility of wheat to feeding by a gall-inducing leafhopper. Naturwissenschaften 98:983-987

Kumashiro S, Matsukura K, Matsumura M, Tokuda M (2012) Distribution of Cicadulina bipunctata (Hemiptera: Cicadellidae) in northern and eastern parts of Kyushu, Japan. Kyushu Pl Prot Res 58:104-109 (in Japanese with English summary)

Li X, Liu Y (2004) The biological characteristics and artificial rearing of Cicadulina bipunctella (Mots). J Southwest Agric Univ 26:143-145 (in Chinese with English summary)

Li X, Liu Y, Tian Y (2004) Effects of six host plants on the development and fecundity of Cicadulina bipunctella. Chin J Appl Ecol 15:1431-1434 (in Chinese with English summary)

Maramorosch K, Calica CA, Agati JA, Pableo G (1961) Further studies on the maize and rice leaf galls induced by Cicadulina bipunctella. Entomol Exp Appl 4:86-89

Matsukura K, Matsumura M (2010) Cultural control of leafhopperinduced maize wallaby ear symptom in forage maize via early planting dates. Crop Prot 29:1401-1409

Matsukura K, Matsumura M, Takeuchi H, Endo N, Tokuda M (2009a) Distribution, host plants, and seasonal occurrence of the maize orange leafhopper, Cicadulina bipunctata (Melichar) (Homoptera: Cicadellidae), in Japan. Appl Entomol Zool 44:207-214

Matsukura K, Matsumura M, Tokuda M (2009b) Host manipulation by the orange leafhopper Cicadulina bipunctata: gall induction on distant leaves by dose-dependent stimulation. Naturwissenschaften 96:1059-1066

Matsukura K, Matsumura M, Tokuda M (2012a) Host feeding by an herbivore improves the performance of offspring. Evol Biol 39:341-347

Matsukura K, Yoshida K, Matsumura M (2012b) Estimation of climatic factors relating to occurrence of the maize orange leafhopper, Cicadulina bipunctata. Popul Ecol 54:397-403

Matsumura S (1914) Die Jassinen und einige neue Acocephalinen Japans. J Coll Agric Tohoku Imp Univ 5:165-240

Matsumura M, Tokuda M (2004) A mass rearing method using rice seedlings for the maize orange leafhopper Cicadulina bipunctata (Melichar) (Homoptera: Cicadellidae) and a simple method for evaluating varietal resistance of maize to maize wallaby ear disease. Kyushu Pl Prot Res 50:35-39 (in Japanese with English summary)
Matsumura M, Tokuda M, Endo N, Ohata S, Kamitani S (2005) Distribution and abundance of the maize orange leafhopper Cicadulina bipunctata (Melichar) (Homoptera: Cicadellidae) in Kikuchi, Kumamoto, Japan, in 2004. Kyushu Pl Prot Res 51:36-40 (in Japanese with English summary)

Matsumura M, Tokuda M, Endo N (2006) Recent outbreaks of the maize orange leafhopper Cicadulina bipunctata inducing galllike structures on maize in Japan. In: Ozaki K, Yukawa J, Ohgushi T, Price PW (eds) Gall arthropods and their associates: ecology and evolution. Springer, Tokyo, pp 149-158

Ofori FA, Francki RIB (1983) Evidence that maize wallaby ear disease is caused by an insect toxin. Ann Appl Biol 103:185-189

Ohata S (1993) The occurrence of maize wallaby ear disease caused by the feeding of leafhopper, Cicadulina bipunctata Melichar (Homoptera, Cicadellidae). Jpn J Glass Sci 39:120-123 (in Japanese)

Ozawa A (2002) Leafminer flies. In: Murakami O, Washitani I (eds) Handbook of Alien Species in Japan. Chijin-shokan, Tokyo, p 140 (in Japanese)

R Development Core Team (2011) R, a language and environment for statistical computing. R Foundation, Vienna. http://www.Rproject.org

Reddy DVR, Grylls NE, Black LM (1976) Electrophoretic separation of dsRNA genome segments from maize wallaby ear virus and its relationship to other phytoreoviruses. Virology 73:36-42

Rose DJW (1972) Dispersal and quality in populations of Cicadulina species (Cicadellidae). J Animal Ecol 41:589-609

Saito T (1992) Outbreak of Liriomyza trifolii Burgess in Japan and its control. Plant Prot 46:103-106 (in Japanese)

Sokal RR, Rohlf FJ (1995) Biometry. Freeman, New York

Tokuda M, Matsumura M (2005) Effect of temperature on the development and reproduction of the maize orange leafhopper Cicadulina bipunctata (Melichar) (Homoptera: Cicadellidae). Appl Entomol Zool 40:213-220

Tokuda M, Jikumaru Y, Matsukura K, Takebayashi Y, Kumashiro S, Matsumura M, Kamiya Y (2013) Phytohormones related to host plant manipulation by a gall-inducing leafhopper. PLoS ONE 8:e62350

Webb MD (1987) Species recognition in Cicadulina leafhoppers (Hemiptera: Cicadellidae), vectors of pathogens of Gramineae. Bull Entomol Res 77:683-712 